\title{
BMJ Open Trends of injury mortality during the COVID-19 period in Guangdong, China: a population-based retrospective analysis
}

\author{
Xue-Yan Zheng, ${ }^{1}$ Si-Li Tang (10 , ${ }^{2}$ Shu-Li Ma, ${ }^{3}$ Wei-Jie Guan, ${ }^{4}$ Xiaojun Xu, ${ }^{1}$ \\ Haofeng Xu, ${ }^{1}$ Ying-Shan Xu, ${ }^{1}$ Yan-Jun Xu, ${ }^{1}$ Li-Feng Lin ${ }^{1,2}$
}

To cite: Zheng X-Y, Tang S-L, Ma S-L, et al. Trends of injury mortality during the COVID-19 period in Guangdong, China: a population-based retrospective analysis. BMJ Open 2021;11:e045317. doi:10.1136/ bmjopen-2020-045317

- Prepublication history and additional materials for this paper is available online. To view these files, please visit the journal online (http://dx.doi. org/10.1136/bmjopen-2020045317).

Y-JX and L-FL contributed equally.

X-YZ, S-LT, S-LM and W-JG are joint first authors.

Received 29 September 2020 Revised 18 January 2021 Accepted 23 February 2021

Check for updates

(c) Author(s) (or their employer(s)) 2021. Re-use permitted under CC BY-NC. No commercial re-use. See rights and permissions. Published by BMJ.

For numbered affiliations see end of article.

Correspondence to

Dr Li-Feng Lin;

1396320174@qq.com and

Yan-Jun Xu;

759888406@qq.com

\section{ABSTRACT}

Objective We aimed to ascertain the trends of injury mortality during the COVID-19 period in southern China. Methods We conducted a population-based retrospective analysis to compare the mortality changes of all-cause injury and transport injuries, poisoning, falls, fire/heat/ hot substances, drowning, self-harm and interpersonal violence, which were further stratified by sex and age. Comparisons were made between the COVID-19 period (between January 2020 and June 2020) and control period (between January 2019 and June 2019) in Guangdong province. We used the negative binomial models to explore the associations of deaths during the COVID-19 period, according to the different sex and age strata.

Results The all-cause injury mortality in Guangdong province decreased significantly from 28.65 per 100000 population during the control period to 23.24 per 100000 population during COVID-19 pandemic period. Similar results were found in specific injury categories. Mortality of self-harm increased by $139.26 \%$ in the $10-14$ year group during the COVID-19 period as compared with the control period. Although mortality changes in some groups were not statistically significant, some increases were noteworthy during the COVID-19 period (ie, self-harm, transport injury and falls) in the 70-79 year group. The corresponding increase in mortality rate was $16.83 \%$, $3.32 \%$ and $4.92 \%$, respectively.

Conclusion The mortality of all-cause injury, transport injury and drowning during the COVID-19 pandemic was consistently decreased. However, the increase in mortality associated with falls, fire/heat/hot substance injury and self-harm in specific age populations warrant the targeted control and prevention measures for the population at risk.

\section{INTRODUCTION}

Recent studies have shown that the COVID-19 pandemic confers a profound effect on all aspects of the society that has been extended to the mental health. Significant decreases in the rate of acute coronary syndrome-related hospitalisation and outpatient visits have been reported in Italy during the early COVID-19 outbreak. ${ }^{12}$ The projected increases in suicide have also been linked to the COVID-19 outbreak in Canada. ${ }^{3}$ The vicarious traumatisation scores of the

\section{Strengths and limitations of this study}

This is the first study comparing the injury mortality between the COVID-19 period and the control period.

- The completeness of death surveillance in Guangdong province was estimated using an empirical method to minimise under-reporting.

- The causative effect of the COVID-19 epidemic on injury mortality could not be confirmed due to the limitation of the observational study design.

- There was a lack of injury incidence, which should be regarded as another limitation of measuring the injury-associated burden.

general public have recently been shown to be significantly higher than those of the frontline nurses. ${ }^{4}$ Different levels of psychological impacts (including stress, anxiety and depression) might have accounted for the increase in the suicidal events. Multidisciplinary research priorities for the COVID-19 pandemic have called for an urgent action for mental health science. ${ }^{5}$

During the COVID-19 pandemic, strict quarantine measures have been introduced to curb the transmission of SARS-CoV-2 in mainland China, including the people who have not contracted COVID-19. ${ }^{6}$ Guangdong is a major province that has suffered from one of the major massive epidemics of COVID-19 in mainland China. The government had enforced stringent quarantine and lockdown measures with an unprecedented effort to contain the COVID-19 outbreak. Except for those who were responsible for providing the daily necessities and emergency services, the workforce has ceased working since the Chinese Lunar Calendar New Year (24 January 2020) and were requested to return to work after 10 February 2020. COVID-19 has also markedly dampened the global social orders and economy. ${ }^{7}$

Guangdong province has 108 million permanent residents that account for $8.03 \%$ 
of the population in mainland China. Twenty-one cities with 122 counties are located in Guangdong province. Compared with other provinces, Guangdong has achieved the highest gross domestic product and become the most developed province with the largest population in southern China. Currently, little is known about the mortality changes of injury (including suicide) in different age and sex strata during the COVID-19 period in southern China.

We hypothesised that there would be both physical and mental health issues caused by the lockdown and quarantine measures during the COVID-19 period. We sought to ascertain the injury mortality changes in Guangdong province. Our findings might help provide the evidence about the status quo of injury and metal health, as well as the guidance and actionable information for governments and public health authorities during the COVID-19 pandemic.

\section{METHODS AND MATERIAL}

\section{Study design and data source}

We conducted a population-based retrospective analysis to compare the mortality changes of injury in different categories (including transport injuries, poisonings, falls, fire/heat/hot substances, drowning, self-harm and interpersonal violence, which were stratified by sex and age) between the study and control period. The study period was defined as the duration between the date of the identification of the first cases and the date when quarantine measures were implemented in Guangdong province (1 January 2020) and the data cut-off (30 June 2020). The control period was defined as a corresponding period during the previous year (from 1 January 2019 to 30 June 2019). Death registration is an all-cause of death surveillance that covers the whole population residing in Guangdong province. Mortality data were derived from the Chinese Center for Disease Control and Prevention (CDC) Cause of Death Reporting System. ${ }^{8}$

\section{Definition of major injury category}

Injury deaths were identified according to the International Classification Of Diseases (ICD-10) codes as recommended by the US CDC, ${ }^{910}$ based on the diagnostic codes of V01-Y89. Based on published studies and the ICD-10 codes of injury, we selected several categories of injury: transport injuries (V01-V04, V06, V09-V80, V87, V89 and V99), poisonings (X40-X49), falls (W00-W19), fire, heat and hot substances (X00-X09), drowning (W65W74), self-harm (X60-X84 and Y87.0) and interpersonal violence (X85-Y09 and Y87.1).

\section{Statistical analyses}

The registered population number in different age and sex strata in both 2019 and 2020 that corresponded to different cities in Guangdong province were obtained from the Population Basic Information System, which served as the denominators for mortality calculation. The
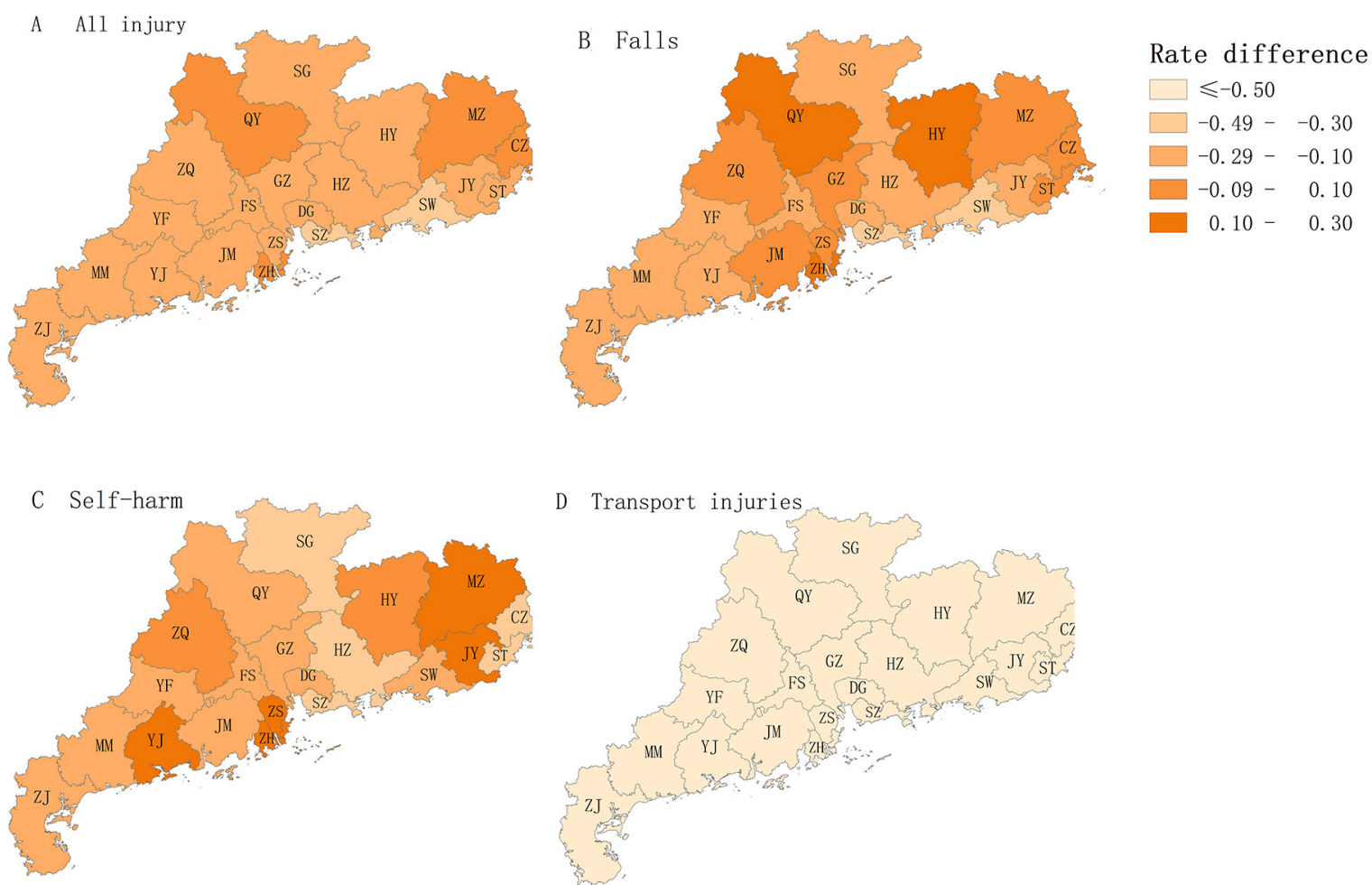

Figure 1 All injury, transport injuries, falls and self-harm mortality changes between the COVID-19 pandemic period and control period in 21 cities in Guangdong province, China. CZ, Chaozhou; DG, Dongguan; FS, Foshan; GZ, Guangzhou; HY, Heyuan; HZ, Huizhou; JM, Jiangmen; JY, Jieyang; MM, Maoming; MZ, Meizhou; QY, Qingyuan; SG, Shaoguan; ST, Shantou; SW, Shanwei; SZ, Shenzhen; YF, Yunfu; YJ, Yangjiang; ZH, Zhuhai; ZJ, Zhanjiang; ZQ, Zhaoqing; ZS, Zhongshan. 
Table 1 Comparison of mortality for injury causes between the onset of the COVID-19 outbreak and the control period in Guangdong province

\begin{tabular}{|c|c|c|c|c|}
\hline Injury subtypes & Study period $(1 / 100$ 000) & Control period (1/100 000) & Changes (\%) & $P$ value \\
\hline All cause of injury & 23.24 & 28.65 & -18.86 & $<0.0001$ \\
\hline Transport injuries & 5.06 & 7.11 & -28.80 & $<0.0001$ \\
\hline Falls & 8.45 & 9.31 & -9.30 & $<0.0001$ \\
\hline Fire, heat and hot substances & 0.17 & 0.24 & -28.41 & 0.012 \\
\hline Self-harm & 3.04 & 3.73 & -18.46 & $<0.0001$ \\
\hline Interpersonal violence & 0.16 & 0.29 & -43.19 & $<0.0001$ \\
\hline
\end{tabular}

percentage changes were calculated with the following formula:

$\frac{\text { Mortality in COVID-19 period - Mortality in control period in } 2019}{\text { Mortality in control period in } 2019} \times 100 \%$

The completeness of death surveillance in Guangdong province was estimated empirically. ${ }^{11}$ Briefly, the following equation was applied to predict the completeness for both sexes:

$$
\begin{aligned}
\operatorname{logit}\left(\mathrm{C}^{\mathrm{All}}\right) & =(\operatorname{RegCDRsq} \times-0.0238)+(\operatorname{RegCDR} \times 0.8419) \\
& +(\% 65 \times-19.6118)+(\ln (5 \mathrm{q} 0) \times-1.5135) \\
& +(\text { Year } \times-0.0251)+44.3755+\gamma
\end{aligned}
$$

where $C^{A l l}$ was the completeness of the registration of all ages, $\operatorname{logit}\left(C^{A l l}\right)$ equalled to $\ln \left(\frac{\mathrm{C}^{\text {All }}}{1-\mathrm{C}^{\text {All }}}\right), \operatorname{Reg} C D R$ was the registered crude death rate (CDR), RegCDRsq was the square of $\operatorname{Reg} C D R, \% 65$ was the fraction of the population aged 65 years or greater, $\ln (5 q 0)$ was the natural $\log$ of the under-5 mortality rate, Year was calendar year and $\gamma$ was a random effect. The predicted completeness was converted by using the inverse logit: $\frac{\mathrm{e}^{\operatorname{logit}\left(C^{\text {All }}\right)}}{\mathrm{e}^{\operatorname{logit}\left(C^{\mathrm{All}}\right)}+1}$

Because of the overdispersion of injury deaths, we used negative binomial models to explore the associations of deaths within the COVID-19 period in different sex and age strata. ${ }^{1213}$ All statistical analyses were conducted using Stata statistical software V.12.1. Differences were considered statistically significant in the two-tailed tests if the $\mathrm{p}$ values were less than 0.05 .

\section{Patient and public involvement}

No patient involved.

\section{RESULTS}

The completeness was $97.03 \%$ and $98.53 \%$ based on the empirical estimation, respectively. The all-cause injury mortality in Guangdong province decreased from 28.65 per 100000 population in the control period to 23.24 per 100000 people in the COVID-19 pandemic $(\mathrm{p}<0.05)$. Furthermore, the mortality of specific injury categories including transport injuries (5.06 per 100000 population vs 7.11 per 100000 population), poisonings (1.04 per 100000 population vs 1.18 per 100000 population), falls
(8.45 per 100000 population vs 9.31 per 100000 population), fire, heat and hot substances (0.17 per 100000 population vs 0.24 per 100000 population), drowning (1.23 per 100000 population vs 1.87 per 100000 population), self-harm (3.04 per 100000 population vs 3.73 per 100000 population) and interpersonal violence $(0.16$ per 100000 population vs 0.29 per 100000 population) decreased significantly during the COVID-19 pandemic as compared with the control period (all $\mathrm{p}<0.05$, figure 1 , table 1).

The mortality from all-cause and specific category injuries (including transport injuries, falls, fire/heat/ hot substances, drowning, self-harm and interpersonal violence) decreased significantly in the total population and in both males and females, with exception of heat and hot substances in females (figure 2, table 2). Stratification of the study population into different age strata revealed a significantly increased mortality. The self-harm mortality in the 10-14 year group significantly increased
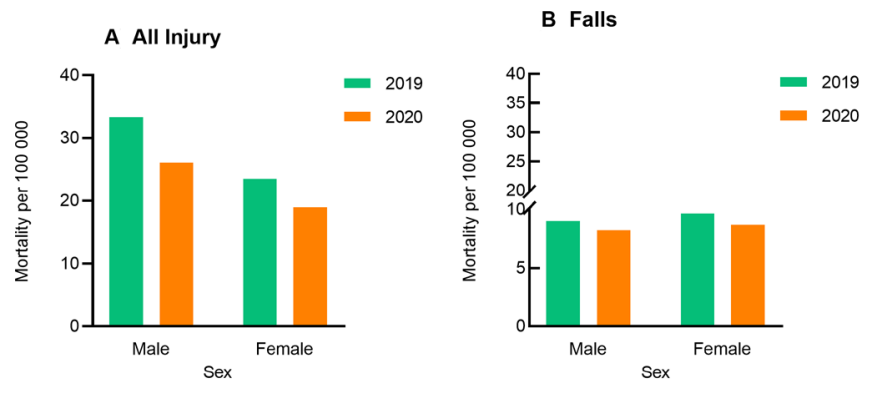

C Self-harm

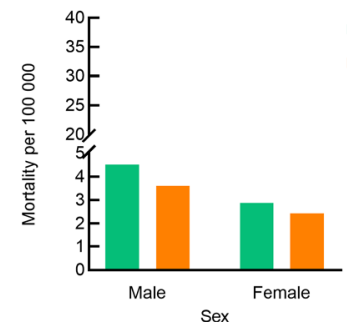

D Transport Injuries

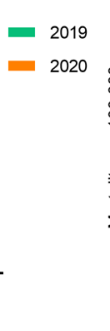

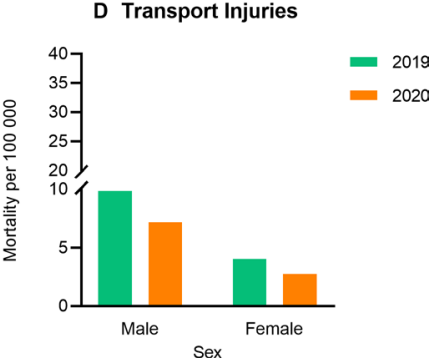

Figure 2 All injury, transport injuries, falls and self-harm in different sex groups between the COVID-19 pandemic period and control period in Guangdong province, China. 


\begin{tabular}{|c|c|c|c|c|c|c|c|c|c|}
\hline Sex strata & $\begin{array}{l}\text { Age } \\
\text { group }\end{array}$ & $\begin{array}{l}\text { Transport } \\
\text { injuries }\end{array}$ & Poisonings & Falls & $\begin{array}{l}\text { Fire, heat and } \\
\text { hot substances }\end{array}$ & Drowning & Self-harm & $\begin{array}{l}\text { Interpersonal } \\
\text { violence }\end{array}$ & $\begin{array}{l}\text { All-cause } \\
\text { of injury }\end{array}$ \\
\hline \multirow[t]{4}{*}{ Male } & $0-14$ & $-32.25^{\star}$ & -39.30 & -13.19 & $-69.83^{*}$ & -19.32 & $\begin{array}{l}151.49^{*} \\
(10-14 \\
\text { years) }\end{array}$ & 56.90 & $-22.50^{*}$ \\
\hline & $70-79$ & 7.44 & -0.94 & 6.75 & -40.91 & $-41.31^{*}$ & 21.41 & 87.11 & 2.71 \\
\hline & $80+$ & -13.68 & -6.54 & 5.45 & 32.16 & -15.04 & $-43.68^{\star}$ & 3.84 & 0.53 \\
\hline & Total & $-27.06^{\star}$ & -9.16 & $-8.72^{*}$ & $-39.99^{*}$ & $-30.90^{\star}$ & $-20.19^{\star}$ & $-40.54^{\star}$ & $-19.56^{\star}$ \\
\hline \multirow[t]{4}{*}{ Female } & $0-14$ & $-36.34^{*}$ & -35.24 & -8.50 & -6.46 & $-55.27^{\star}$ & $\begin{array}{l}127.00^{*} \\
(10-14 \\
\text { years) }\end{array}$ & -48.98 & $-37.04^{*}$ \\
\hline & $70-79$ & -2.53 & -22.83 & 3.49 & 49.58 & -0.44 & 12.40 & -28.77 & 2.51 \\
\hline & $80+$ & $-33.09^{*}$ & 101.69 & $-6.87^{*}$ & 31.10 & $-42.37^{*}$ & 0.85 & 0.85 & $-6.86^{\star}$ \\
\hline & Total & $-32.78^{*}$ & -16.62 & $-9.93^{*}$ & -1.21 & $-40.67^{*}$ & $-15.17^{\star}$ & $-46.06^{\star}$ & $-17.58^{\star}$ \\
\hline \multirow[t]{5}{*}{$\begin{array}{l}\text { General } \\
\text { population }\end{array}$} & $0-14$ & $-34.07^{\star}$ & $-36.68^{*}$ & -11.18 & -52.00 & $-31.89^{*}$ & $\begin{array}{l}139.26^{*} \\
(10-14 \\
\text { years) }\end{array}$ & -16.00 & $-28.87^{\star}$ \\
\hline & $15-59$ & $-32.71^{*}$ & $-13.13^{*}$ & $-15.56^{\star}$ & $-44.10^{*}$ & $-35.25^{\star}$ & $-22.67^{\star}$ & $-51.68^{\star}$ & $-25.99^{*}$ \\
\hline & $60-69$ & $-38.81^{*}$ & -3.04 & $-27.01^{*}$ & -31.62 & $-48.12^{*}$ & $-27.24^{*}$ & -45.90 & $-32.22^{*}$ \\
\hline & $70-79$ & 3.32 & -12.44 & 4.92 & -22.48 & -20.40 & 16.83 & 27.69 & 2.12 \\
\hline & $80+$ & -21.92 & 29.26 & -2.45 & 31.20 & $-33.03^{*}$ & -22.78 & 2.05 & -4.04 \\
\hline
\end{tabular}

*Statistical significance using negative binomial model for comparison of COVID-19 period and control period in 2019 ( $p<0.05)$.

in males, females and the general population. Although the increased mortality of self-harm, transport injury, falls and interpersonal violence in the $70-79$ year group did not reach statistical significance, the increase in mortality in this age group was noteworthy. Moreover, there was an insignificant increase in mortality from fire, heat and hot substances in the $80+$ year group in both sexes as well as from falls in the $80+$ year group among males (figure 3, table 2).

The number of deaths due to all-cause injuries and specific types of injuries in different age groups and cities are provided in the online supplementary material (online supplemental eTable 1-3).

\section{DISCUSSION}

Our study revealed that the mortality from all-cause injury and specific categories of injury (including transport injuries, poisonings, falls, fire/heat/hot substances, drowning, self-harm and interpersonal violence) has decreased dramatically, which might have resulted from the COVID-19 pandemic. However, stratification of the study population into different city, age and sex strata has unravelled a significantly increased mortality in certain types of injury. Despite that the mortality changes in some strata did not reach statistical significance, there has been a notably increased mortality during the COVID-19 period (ie, self-harm, transport injury, falls and interpersonal violence in the 70-79 year group). This has shed light on the priorities and longer term strategies for injury and mental health scientific research, control and prevention. To our knowledge, this is the first study that demonstrated the injury mortality at different age and sex strata at the provincial level in mainland China. Our findings have added new insights by providing comparisons between the COVID-19 pandemic period and the control period in 2019.

Because our study was conducted during the COVID-19 pandemic when stringent lockdown and quarantine measures were enforced in mainland China, the most prominent impact of COVID-19 on injury could not be fully captured. During the COVID-19 outbreak, most people avoided outdoor activities to minimise the use of healthcare services and avoid the SARS-CoV-2 infection. Consequently, there has been a notable decrease in the mortality from transport injury and drowning at all age strata. Similar results have been documented in the UK ${ }^{14}$ and India. ${ }^{15}$ Degenerative spine and traumatic brain injuries also decreased significantly during the COVID-19 

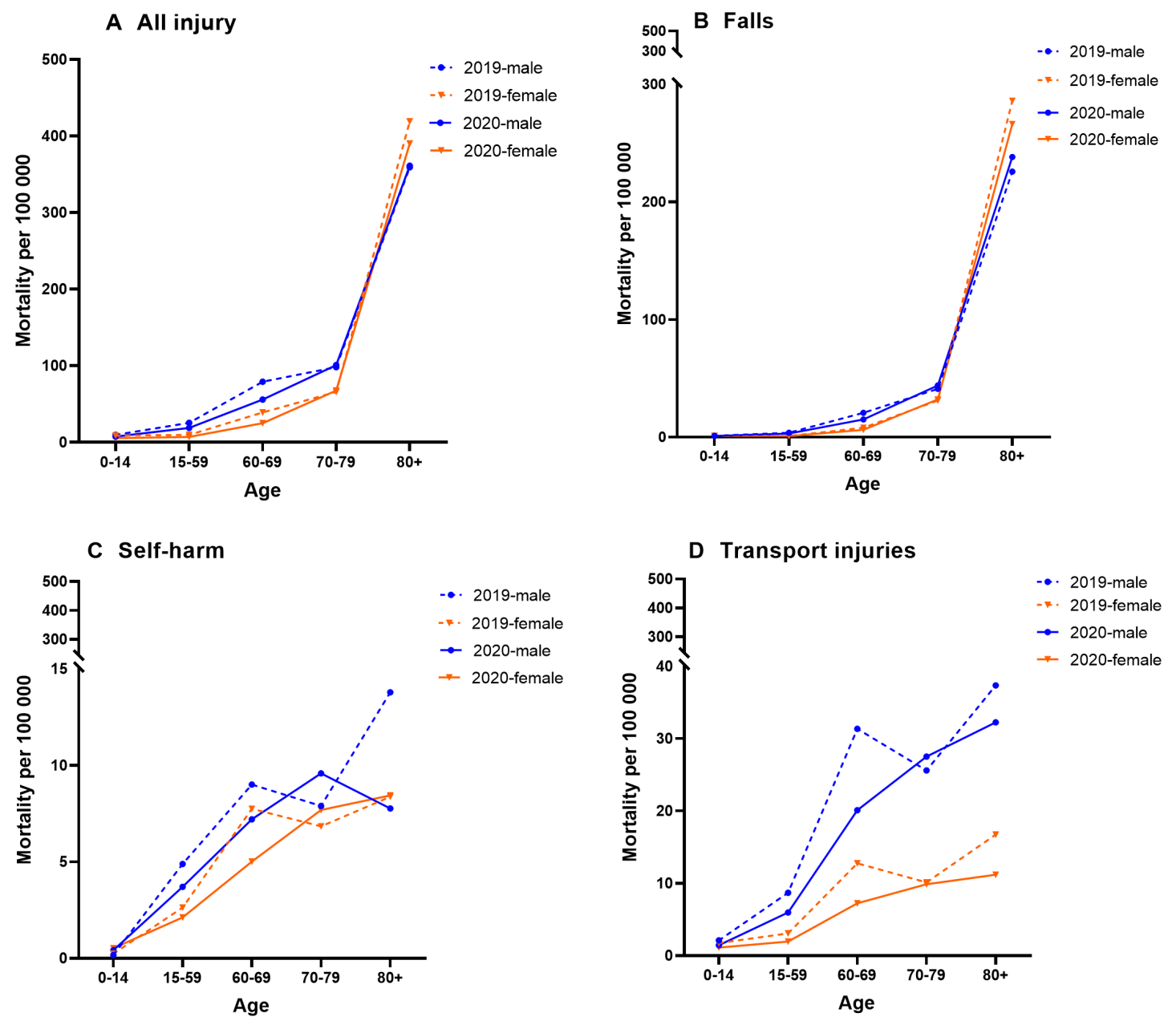

Figure 3 All injury, transport injuries, falls and self-harm mortality changes in different age and sex groups between the COVID-19 pandemic period and control period in Guangdong province, China.

pandemic in UK. ${ }^{14}$ The lockdown has grossly decreased the disability-adjusted life years caused by road traffic injury. $^{15}$

It remains unclear why the mortality of fire, heat and hot substances in the general population decreased during the COVID-19 period based on the existing data and literature reports. In line with our study, some researchers have demonstrated a higher mortality in the elderly. ${ }^{1617}$ In the UK, scalds accounted for $60 \%$ of the deaths of fire, heat and hot substances in the $>75$ year group. ${ }^{18}$ By contrast to the findings from the previous study, fire or smoke inhalation caused by fire are the main causes of the increased mortality among the elderly during the COVID-19 period in our study. People who died from fire, heat and hot substances were reported from the rural areas, where the elderly living alone were more likely to use biomass fuel (ie, wood, coal, animal dung and crop residues) for cooking and heating. A comprehensive strategy that integrates public education, distribution of firefighting equipment, adequate supervision for the vulnerable adults while heating and cooking and the use of ageing electric appliance in the elderly would be indispensable to improve public health.
The causes of death from interpersonal violence have been multifactorial. Theoretically, unemployment and fear of acquiring COVID-19 would have predisposed to an increased incidence of household interpersonal violence that has been non-fatal. By contrast, both the incidence and mortality of social interpersonal violence would sharply decrease because of the stringent lockdown and quarantine measures that might have been fatal. The decrease in the mortality associated with social interpersonal violence might have largely been offset by the nonfatal incidence of household interpersonal violence.

The death rate of falls has been declining despite a notable increase in the elderly, which is probably due to the increased life expectancy in the past two decades. A greater proportion of the elderly living with chronic diseases were at risk of falls. ${ }^{19}$ This tended to be aggravated during the COVID-19 period because the elderly remain exposed to trauma due to domestic falls with a reduced number of healthcare services. ${ }^{20}$ In this scenario, the elderly suffered from a increased risk of having disability or death due to the delayed care and treatment for fallrelated injuries. ${ }^{21} 22$ Given the relatively high burden of falls among the elderly, a systematic implementation 
to reduce the incidence of injuries from falls would be urgently needed. These measures include a sufficient medical and occupational therapy ${ }^{23}$ professional environment hazard assessment and modification, ${ }^{24}$ vitamin $\mathrm{D}$ and calcium supplementation, hip protectors and reduction of many of the predisposing risk factors. ${ }^{25}$

Self-harm is becoming a more pressing concern as the pandemic is spreading rapidly and has the longer term effects on the general population, the economy and the vulnerable population. The infectious disease epidemics seemed to serve as a catalyst to trigger the suicidal attempt of people with mental health disorders. ${ }^{26}{ }^{27}$ Our results revealed an increased death rate for self-harm in the 10-14 year and 70-79 year group in both sexes. The likely adverse effects of the pandemic on children's mental health might be exacerbated by fear of being infected by SARS-CoV-2, self-isolation and physical distancing because of school closure. ${ }^{28}$ These contributed to an increase in the prevalence of post-traumatic stress disorder symptoms, depression, anxiety and stress. ${ }^{29}$ In conjunction with a higher risk of being exposed to the family conflicts, the household physical violence, academic stress and economic damage that were caused by the COVID-19 crisis might have collectively led to an increased rate of suicide among children. ${ }^{30} \mathrm{~A}$ loss of employment, financial stressors and alcohol consumption, which have also been the well-recognised risk factors causing family conflict, ${ }^{31}$ might have aggravated during the lockdown. Despite of the mental health disorders and the family conflict, the elderly might be increasingly concerned because of the extraordinarily high case fatality rate. ${ }^{32}$ This might have also contributed to the increased risk of self-harm in the elderly. Selective and universal interventions are required for the targeted individuals at risk of suicide, including sharing the evidence-based interventions online, increasing volunteer workforce for crisis hot lines and providing financial safety nets for unemployment support. ${ }^{33}$ Public health responses must ensure that those facing interpersonal violence are supported and that safe drinking messages are communicated, particularly for the bereaved individuals. Accessible health education and promotion for COVID-19 is recommended, because a study has reported that people who were proactively engaged in hand hygiene could have a decreased likelihood that the workforce experience psychiatric symptoms. ${ }^{29} 34$

Some limitations should be addressed. There was a lack of reliable injury incidence data. Therefore, the comparability of mortality data and incidence data due to the death registration completeness and coverage should be interpreted with caution. Although we have used an empirical method to minimise the underestimation in the death surveillance, the magnitude of completeness of the mortality data varied considerably for children and adult deaths based on the Global Burden of Disease (GBD) 2010 study's finding. ${ }^{35}$ The completeness of data in children was usually lower than that in adults in Latin America and Asia. Second, caution should also be exercised regarding the causative effect of the COVID-19 epidemic on injury mortality because of the limitation of the observational study design.

Despite these limitations, our findings remained robust. The death registration is an all-cause death surveillance that covered all the population residing in Guangdong province. Data from the registration system in the recent years have been aligning well with the vital registration data that achieved a large increase in the coverage over the past decade. ${ }^{36}$

In conclusion, the COVID-19 pandemic was associated with a decreased mortality of all injury, transport injury and drowning. However, the increase in the mortality of falls, fire, heat and hot substances injury, self-harm in specific age populations during the COVID-19 period still warrant the targeted and universal interventions for the mass public.

\section{Author affiliations}

${ }^{1}$ Guangdong Provincial Center for Disease Control and Prevention, Guangzhou, Guangdong, China

${ }^{2}$ School of Public Health, Southern Medical University, Guangzhou, China ${ }^{3}$ Department of Epidemiology and Biostatistics, Guangdong Pharmaceutical University, Guangzhou, Guangdong, China

${ }^{4}$ State Key Laboratory of Respiratory Disease and National Clinical Research Center for Respiratory Disease, the First Affiliated Hospital of Guangzhou Medical University, Guangzhou, Guangdong, China

Contributors XX, HX, Y-SX, Y-JX and L-FL conceived of the study and provided overall guidance. $X-Y Z, S-L T, S-L M, W-J G$ and L-FL prepared the first draft and finalised the manuscript based on comments from all other authors and reviewer feedback. X-YZ, W-JG, Y-JX and L-FL played a key role in formulating the analysis. All other authors contributed to the analysis and reviewed the manuscript.

Funding The authors have not declared a specific grant for this research from any funding agency in the public, commercial or not-for-profit sectors.

Map disclaimer The depiction of boundaries on this map does not imply the expression of any opinion whatsoever on the part of BMJ (or any member of its group) concerning the legal status of any country, territory, jurisdiction or area or of its authorities. This map is provided without any warranty of any kind, either express or implied.

Competing interests None declared.

Patient consent for publication Not required.

Provenance and peer review Not commissioned; externally peer reviewed.

Data availability statement Data are available on reasonable request. All data relevant to the study are included in the article or uploaded as supplementary information.

Supplemental material This content has been supplied by the author(s). It has not been vetted by BMJ Publishing Group Limited (BMJ) and may not have been peer-reviewed. Any opinions or recommendations discussed are solely those of the author(s) and are not endorsed by BMJ. BMJ disclaims all liability and responsibility arising from any reliance placed on the content. Where the content includes any translated material, BMJ does not warrant the accuracy and reliability of the translations (including but not limited to local regulations, clinical guidelines, terminology, drug names and drug dosages), and is not responsible for any error and/or omissions arising from translation and adaptation or otherwise.

Open access This is an open access article distributed in accordance with the Creative Commons Attribution Non Commercial (CC BY-NC 4.0) license, which permits others to distribute, remix, adapt, build upon this work non-commercially, and license their derivative works on different terms, provided the original work is properly cited, appropriate credit is given, any changes made indicated, and the use is non-commercial. See: http://creativecommons.org/licenses/by-nc/4.0/.

ORCID iD

Si-Li Tang http://orcid.org/0000-0002-3687-3458 


\section{REFERENCES}

1 Baldi E, Sechi GM, Mare C, et al. Out-of-hospital cardiac arrest during the Covid-19 outbreak in Italy. N Engl J Med 2020;383:496-8.

2 De Filippo O, D'Ascenzo F, Angelini F, et al. Reduced rate of hospital admissions for ACS during Covid-19 outbreak in northern Italy. $N$ Engl J Med 2020;383:88-9.

3 Mclntyre RS, Lee Y. Projected increases in suicide in Canada as a consequence of COVID-19. Psychiatry Res 2020;290:113104.

$4 \mathrm{Li} \mathrm{Z,} \mathrm{Ge} \mathrm{J,} \mathrm{Yang} \mathrm{M,} \mathrm{et} \mathrm{al.} \mathrm{Vicarious} \mathrm{traumatization} \mathrm{in} \mathrm{the} \mathrm{general}$ public, members, and non-members of medical teams Aiding in COVID-19 control. Brain Behav Immun 2020;88:916-9.

5 Holmes EA, O'Connor RC, Perry VH, et al. Multidisciplinary research priorities for the COVID-19 pandemic: a call for action for mental health science. Lancet Psychiatry 2020;7:547-60.

6 Hao F, Tan W, Jiang L, et al. Do psychiatric patients experience more psychiatric symptoms during COVID-19 pandemic and lockdown? A case-control study with service and research implications for immunopsychiatry. Brain Behav Immun 2020;87:100-6.

7 Gautam R, Sharma M. 2019-nCoV pandemic: a disruptive and stressful atmosphere for Indian academic fraternity. Brain Behav Immun 2020;88:948-9.

8 Zhou M, Wang $\mathrm{H}$, Zhu J, et al. Cause-specific mortality for 240 causes in China during 1990-2013: a systematic subnational analysis for the global burden of disease study 2013. Lancet 2016;387:251-72.

9 Faul M, Xu L, Wald MM. Traumatic brain injury in the United States: emergency department visits, hospitalizations and deaths 2002-2006. Atlanta: US Centers for Disease Control and Prevention, 2010.

10 Thurman DJ, Sniezek JE, Johnson D. Guidelines for surveillance of central nervous system injury. Washington, DC: US Department of Health and Human Services, 1995.

11 Adair T, Lopez AD. Estimating the completeness of death registration: an empirical method. PLoS One 2018;13:e0197047.

12 Adams RS, Larson MJ, Corrigan JD, et al. Traumatic brain injury among U.S. active duty military personnel and negative drinkingrelated consequences. Subst Use Misuse 2013;48:821-36.

13 Statistical Consulting Group. Negative binomial regression: Stata annotated output. Available: https://stats.idre.ucla.edu/stata/output/ negative-binomial-regression/ [Accessed 1 Jun 2017].

14 Jayakumar N, Kennion O, Villabona AR, et al. Neurosurgical referral patterns during the coronavirus disease 2019 pandemic: a United Kingdom experience. World Neurosurg 2020;144:e414-20.

15 Jain A, Goyal V, Varma C. Reflection of epidemiological impact on burden of injury in tertiary care centre, pre-COVID and COVID era: "lockdown, a good fortune for saving life and limb". Indian J Surg 2020;24:1-5.

16 Sadeghian F, Saeedi Moghaddam S, Saadat S, et al. The trend of burn mortality in Iran - A study of fire, heat and hot substance-related fatal injuries from 1990 to 2015. Burns 2019;45:228-40.

17 Tang K, Jian L, Qin Z, et al. Characteristics of burn patients at a major burn center in Shanghai. Burns 2006;32:1037-43.

18 Hussain A, Dunn K. Burn related mortality in greater Manchester: 11 -year review of regional coronial department data. Burns 2015;41:225-34.
19 Centers for Disease Control and Prevention. Fatalities and injuries from falls among older adults, United States, 1993-2003 and 2001-2005. MMWR Morb Mortal Wkly Rep 2006;55:1221-4.

20 Gumina S, Proietti R, Polizzotti G. The impact of COVID-19 on shoulder and elbow trauma: an Italian survey. J Shoulder Elbow Surg 2020;S1058-2746:30401-8.

21 Tong HJ, Huang CY. Changes of family structure and their social influence in contemporary China. Xi Bei Ren Kou Za Zhi 2015;6:81-4.

22 Gao M, Li Y, Zhang S, et al. Does an empty nest affect elders' health? Empirical evidence from China. Int J Environ Res Public Health 2017;14:E463.

23 Close J, Ellis M, Hooper R, et al. Prevention of falls in the elderly trial (PROFET): a randomised controlled trial. Lancet 1999;353:93-7.

24 Keall MD, Pierse N, Howden-Chapman P, et al. Home modifications to reduce injuries from falls in the home injury prevention intervention (HIPI) study: a cluster-randomised controlled trial. Lancet 2015;385:231-8.

25 Kannus P, Sievänen $\mathrm{H}$, Palvanen $\mathrm{M}$, et al. Prevention of falls and consequent injuries in elderly people. Lancet 2005;366:1885-93.

26 Wasserman IM. The impact of epidemic, war, prohibition and media on suicide: United States, 1910-1920. Suicide Life Threat Behav 1992;22:240-54.

27 Cheung YT, Chau PH, Yip PSF. A revisit on older adults suicides and severe acute respiratory syndrome (SARS) epidemic in Hong Kong. Int J Geriatr Psychiatry 2008;23:1231-8.

28 Yao H, Chen J-H, Xu Y-F. Patients with mental health disorders in the COVID-19 epidemic. Lancet Psych 2020;7:e21.

29 Wang C, Pan R, Wan X, et al. A longitudinal study on the mental health of general population during the COVID-19 epidemic in China. Brain Behav Immun 2020;87:40-8.

30 Hoekstra PJ. Suicidality in children and adolescents: lessons to be learned from the COVID-19 crisis. Eur Child Adolesc Psychiatry 2020;29:737-8.

31 Stuckler D, Basu S, Suhrcke M, et al. The public health effect of economic crises and alternative policy responses in Europe: an empirical analysis. Lancet 2009;374:315-23.

32 Guan W-J, Liang W-H, Zhao Y, et al. Comorbidity and its impact on 1590 patients with COVID-19 in China: a nationwide analysis. Eur Respir J 2020;55:2000547.

33 Gunnell D, Appleby L, Arensman E, et al. Suicide risk and prevention during the COVID-19 pandemic. Lancet Psychiatry 2020;7:468-71.

34 Tan W, Hao F, Mclntyre RS, et al. Is returning to work during the COVID-19 pandemic stressful? A study on immediate mental health status and psychoneuroimmunity prevention measures of Chinese workforce. Brain Behav Immun 2020;87:84-92.

35 Lozano R, Naghavi M, Foreman K, et al. Global and regional mortality from 235 causes of death for 20 age groups in 1990 and 2010: a systematic analysis for the global burden of disease study 2010 . Lancet 2012;380:2095-128.

36 GBD 2017 Mortality Collaborators. Global, regional, and national age-sex-specific mortality and life expectancy, 1950-2017: a systematic analysis for the global burden of disease study 2017. Lancet 2018;392:1684-735. 